\title{
Surface functionalization of thermoset composite for infrared hybrid welding
}

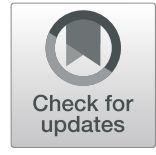

\author{
Henri Perrin*, Grégory Mertz, Noha-Lys Senoussaoui, Loïc Borghini, Sébastien Klein and Régis Vaudemont
}

\begin{abstract}
Fusion assembly is a highly promising technique for joining thermoplastic composite to thermoset composites, enabling the use of both the most affordable composite material and process for each substructure. However, some major challenges need to be addressed such as functionalizing the thermoset composite surface through cocuring with an appropriate thermoplastic interlayer or realizing a fast and robust welding process that meets all quality and mechanical requirements. In this paper, we investigated the potential of polyetheretherketone (PEEK) and its amorphous (PEEK A) and semicristalline (PEEK SC) states as interlayer materials, co-cured onto thermoset composites. A surface preparation involving the atmospheric plasma process demonstrated that both PEEK state materials can be used as interlayer with favorable adhesion properties. The influence of the plasma treatment on surface properties and morphology was also experimentally characterized.
\end{abstract}

Keywords: Infrared welding, Thermoset composite, Thermoplastic composite, Dissimilar joining

An infrared (IR) welding process, barely studied in the literature, was studied to assemble hybrid structural composite. To avoid the expected thermal degradation of the thermoset matrix, dissimilar infrared heating input power is proposed. Single lap shear tests and failure mode analysis were performed to highlight the promising performance of polyetherimide (PEI) as well as PEEK interlayer based hybrid joint.

\section{Introduction}

Aeronautics have to address two main challenges in the upcoming decade: increasing the expected production rate and reducing the cost of composite manufacturing, assembly and control [10]. Indeed, composite materials are a realistic alternative and a key component for reducing both weight and $\mathrm{CO}_{2}$ emissions without affecting mechanical performance. Composites used to replace metallic parts are composed of a reinforcement, generally glass or carbon fibers and a polymeric matrix, being either a thermoset or a thermoplastic. The use of

\footnotetext{
* Correspondence: henri.perrin@list.lu

Material Research and Technology Department, Luxembourg Institute of Science and Technology, 5 rue Bommel, 4940 Hautcharage, Luxembourg
}

thermosets over thermoplastics depends on the application, properties and cost. In the aerospace industry, thermoset based composites (TSCs) are currently being used because of their good compression, fatigue and creep resistance as well as their economical production in the form of large parts. Currently, TSCs are mainly assembled by time and labor consuming bonding/riveting techniques. Conversely, thermoplastic based composites (TPCs) demonstrate high ductility, fracture toughness and impact resistance and can be quickly manufactured by stamping and can be joined to other TPCs by welding.

To produce materials in a more efficient and affordable way, the combination of thermoset and thermoplastic composites, defined here as hybrid composites, opens new design possibilities. Indeed, hybrid composites will enable the use of the right material and the right manufacturing process for the right substructure.

\section{Hybrid welding \\ Dissimilar TSC/TPC welding}

Three main fusion based joining technologies have been explored in the literature to weld together hybrid composites. Resistance welding consists of placing an

\section{Springer Open}

(c) The Author(s). 2021 Open Access This article is licensed under a Creative Commons Attribution 4.0 International License, which permits use, sharing, adaptation, distribution and reproduction in any medium or format, as long as you give appropriate credit to the original author(s) and the source, provide a link to the Creative Commons licence, and indicate if changes were made. The images or other third party material in this article are included in the article's Creative Commons licence, unless indicated otherwise in a credit line to the material. If material is not included in the article's Creative Commons licence and your intended use is not permitted by statutory regulation or exceeds the permitted use, you will need to obtain permission directly from the copyright holder. To view a copy of this licence, visit http://creativecommons.org/licenses/by/4.0/. 
electrical resistance layer, made of metal or carbon fibers at the interface. The Joule effect is used to heat up the interface up to the point of fusion [27]. Since 1980s, induction welding have been developed for polymer and composite welding and processing. A large range of methods, including static, discontinuous or continuous welding, describe the heat and pressure applications process. Induction heating occurs by transforming electromagnetic energy through a conductive interlayer, called a susceptor, or through the conductive properties of the reinforcement fibers, called a susceptorless approach. Ultrasonic (US) welding is well-known for polymer joining applications, but it is still emerging for structural composite material joining. Heat is generated through high-frequency and low-amplitude vibrations, generally concentrated by design singularities at the interface, called the energy director $[6,21]$.

\section{Infrared welding}

Infrared welding is a highly mature welding technology for thermoplastic polymer joining, such as for automotive applications. The relative process simplicity and efficiency and the high level of automation represent strong advantages. Very few authors $[4,15]$ have explored the ability of this technique to join composites.

Regarding the different solutions proposed to join materials by infrared (IR) welding processes, numerous advantages, such as an ability to quickly heat (typically approximately 20-25 s), and a capacity to attenuate contamination risks, allow high productivity rates of reproducible joints in automated systems involving thermoplastic materials as stated by da Costa et al. [6].

Hybrid welding was explored by Asséko et al. [2], by investigating the joining of a glass fiber reinforced polycarbonate composite with carbon black filled polycarbonate. To the best of our knowledge, IR welding has barely been discussed and investigated for joining hybrid high-performance composites.

\section{Thermal degradation during welding}

Thermal degradation during welding represents one of the major constraints for process qualification. Highperformance materials, such as polyetheretherketone (PEEK), present a sensivity to thermal exposure above their melting temperature. In the neat polymer, a weight loss of $0.5 \%$ is observed after $100 \mathrm{~min}$ at $400{ }^{\circ} \mathrm{C}$. Both the enthalpy of fusion and the melting temperature were not modified after $10 \mathrm{~s}$ exposure to $400{ }^{\circ} \mathrm{C}$. At $420{ }^{\circ} \mathrm{C}$, significant changes were observed after $10 \mathrm{~s}$ of exposure in the literatur [18]. More recently, the PEEK thermal stability over a short exposure time have been described by Pascual et al. [17]. The investigation of the through thickness degradation of PEEK indicates that for temperatures below $400{ }^{\circ} \mathrm{C}$, the degradation mechanism is slow. After
$50 \mathrm{~s}$ at $400{ }^{\circ} \mathrm{C}$, no major changes were observed in the melting temperature, crystallinity, or the glass temperature. Above $430{ }^{\circ} \mathrm{C}$, a faster degradation process was observed.

Thermoset composites are definitely much more sensitive to thermal degradation than thermoplastic. To avoid thermal degradation, very short heating times are required Villegas and Rubio [24]. A heating time well under $1 \mathrm{~s}$ is recommended. Such ultrafast heat cycles are only possible by US welding.

\section{TSC surface functionalization Adhesion interlayer/TSC}

In the literature, many authors have explored the use of polyetherimide (PEI) as an interface material for hybrid welding. PEI has been demonstrated to be a good candidate to act as an interfacial layer for thermoset composite. PEI is generally preferred due to its intrinsic miscibility with epoxy resin, which leads to high resulting adhesion properties. However, this advantage also represents a weak point regarding several in-service applications. PEI polymer presents a limited withstand to aeronautical fluids [12, 26, 25]. Nevertheless, there is another challenge to overcome after co-curing: joining the co-cured TSC bearing a thermoplastic rich layer with the other part efficiently and in a short time. Therefore, the welding process needs to provide concentrated heat in a limited time.

PEEK based interlayers for hybrid welding have barely been investigated in the literature. The PEEK interlayer can be used direct be co-curing or coupled with a PEI interlayer [21].

The diffusion of thermoset precursors into thermoplastics is well described in the literature and mainly involves the dissolution of thermoplastic fibers, films or fillers into the thermoset precursor, enabling an increase in the thermoset composite toughness. The most popular tougheners are polysulfone (PSF), polyethersulfone (PES) and PEI, which are typically high glass temperature amorphous thermoplastics. Through the experimental analysis of the thermoplastic filament section embedded in the thermoset matrix, swelling kinetics have been observed by measuring the diffusion distance [5]. The diffusion distance is strongly dependent on the isothermal temperature and duration prior to thermoset crosslinking. At $100{ }^{\circ} \mathrm{C}$, the PES thermoplastic is unaffected by RTM6, an event after $180 \mathrm{~min}$. Otherwise, at $140{ }^{\circ} \mathrm{C}$, the PES section reduction was maximal after 20 to $60 \mathrm{~min}$ as a function of the PES end group. The diffusion efficiency is predominantly controlled by the thermoplastic $\mathrm{Tg}$ [23]. Unlike PES filaments, phenoxy filaments are completely dissolved at $140{ }^{\circ} \mathrm{C}$ after $4 \mathrm{~min}$, although PES and phenoxy have similar average molecular weights. The dramatically lower $\mathrm{Tg}$ of phenoxy 
compared to PES $\left(84{ }^{\circ} \mathrm{C}\right.$ vs. $220{ }^{\circ} \mathrm{C}$ ) promotes thermoplastic chain mobility, inducing faster penetration of the thermoset precursor.

\section{Interlayer surface preparation}

PEEK is known for its poor wettability and poor adhesive properties. A large range of surface treatment methods have been investigated, such as atmospheric plasma, low pressure plasma [28], laser treatment or ultraviolet (UV)irradiation [1]. UV irradiation of PEEK induces chemical structure changes, corresponding to higher absorption values by Fourier transform infrared (FTIR) analysis in the range from $1675 \mathrm{~cm}-1$ to 1800 $\mathrm{cm}-1$ and from $2700 \mathrm{~cm}-1$ to $3600 \mathrm{~cm}-1$. Chain scissoring is considered responsible for this change. By atomic force microscopy (AFM), in both height and phase images, the TSC/PEEK interface was analyzed. A clear interface is visible with as-received PEEK, however, a less obvious interface was observed with irradiated PEEK.

Plasma treatment of high-performance polymers, such as PEEK polymers, and the resulting chemical, physical and topological surface modifications are well described in the literature. Surface chemistry analysis has shown an increase in the oxygen content of the surface region, and increases the surface energy, O:C ratio and surface roughness [16]. The plasma treatment induced surface etching of PEEK has been thoroughly studied by a few authors. The resulting roughness of the PEEK surface after plasma treatment is not consistently described. This can be explained by the first representation of the compared roughness parameters and the initial surface roughness. As an example, the arithmetic average roughness $(\mathrm{Ra})$ increases with the plasma treatment time according to Shi et al. [19] but appears to be unaffected in semicrystalline PEEK according Zhang et al. [28]. The use of less common roughness parameters, such as the total height of profile (Rt) [20] could provide a clearer view of the plasma induced surface roughness. By measuring the vertical distance between the maximum profile peak height and the maximum profile valley depth along the evaluation length, the potential dual-scale roughness, of namely, the initial roughness of the material surface and the secondary roughness induced by the treatment, is not taken into account.

\section{Proposed contribution}

In the present work, a new approach of hybrid thermoset/thermoplastic composites is proposed by welding both composites by automated fast infrared technology. We propose to study the co-curing of three different thermoplastic interlayers, treated with plasma and investigate how co-cured adhesion is driven by plasma treatment and the waiting time after treatment.
Functionalized TSCs are welded by infrared welding, enabling the production of standard testing samples and mechanical performance for each treatment condition and interlayer material conditions.

\section{Experimental procedures \\ Materials for welding \\ Thermoplastic composite}

In this work, a carbon fiber-reinforced PEEK consolidated laminate supplied by Toray Advanced Composites was selected. The $1.86 \mathrm{~mm}$ thick laminate is made of 6 plies of $5 \mathrm{H}$ satin weave from $3 \mathrm{~K} \mathrm{~T} 300$ carbon fiber roving with a quasi-isotropic layup.

\section{Interlayer surface material}

Two references of $25 \mu \mathrm{m}$ PEEK film in an amorphous (PEEK A) and semicristalline (PEEK SC) state (Aptiv 2000 from Victrex ${ }^{\circ}$ ) with matte/gloss finishing were chosen. A $50 \mu \mathrm{m}$ PEI (ULTEM ${ }^{\mathrm{si}}$ from Sabic) film was also included in this study as a reference interlayer. The DSC analysis presented in Fig. 1 shows that PEEK A presents a low level of cristallinity, $8 \%$ as received, compared to the $34,7 \%$ crystallinity of PEEK SC as received. As received, PEEK A presents a slightly lower Tg of $143{ }^{\circ} \mathrm{C}$ than PEEK SC with a Tg of $148.5{ }^{\circ} \mathrm{C}$. PEEK A starts to recrystallize by heating up to $160^{\circ} \mathrm{C}$. Per convention, the matte surface of the films is in contact with the TSC, and the gloss is welded on the TPC.

\section{TSC surface functionalization}

\section{Interlayer surface treatment by plasma}

Plasma treatments were performed using an atmospheric pressure dielectric barrier discharge (DBD) reactor. Briefly, plasma was ignited in a DBD ( $3 \mathrm{~mm}$ gap between the electrodes) in which each of the two high voltage aluminum plate electrodes was protected by a $3.25 \mathrm{~mm}$ thick glass plate. Plasma discharge was generated by an AC power supply set at $450 \mathrm{~W}$ and $6 \mathrm{kHz}$, with a flow of $80 \% \mathrm{~N}_{2}$ and $20 \% \mathrm{O}_{2}$. The top electrode moved over the bottom electrode at a constant speed of $4 \mathrm{~m}$.min 1 . The deposition time was set to $1 \mathrm{~min}$.

Through the proposed surface treatment by N2/ $\mathrm{O} 2(80 / 20)$ atmospheric plasma [14], the wettability of the three interlayer films was improved through cleaning and chemical activation. To better understand the time contribution of the treated surface and the hydrophobic recovery that can occur at the surface over time, tests were performed just after plasma treatment and then after 1 and 7 days on samples stored under ambient atmosphere conditions to evaluate their stability. An interlayer film without treatment of each interlayer material was also included. In the present work, a table summarizes the different thermoplastic interlayers used and the treatments performed. 

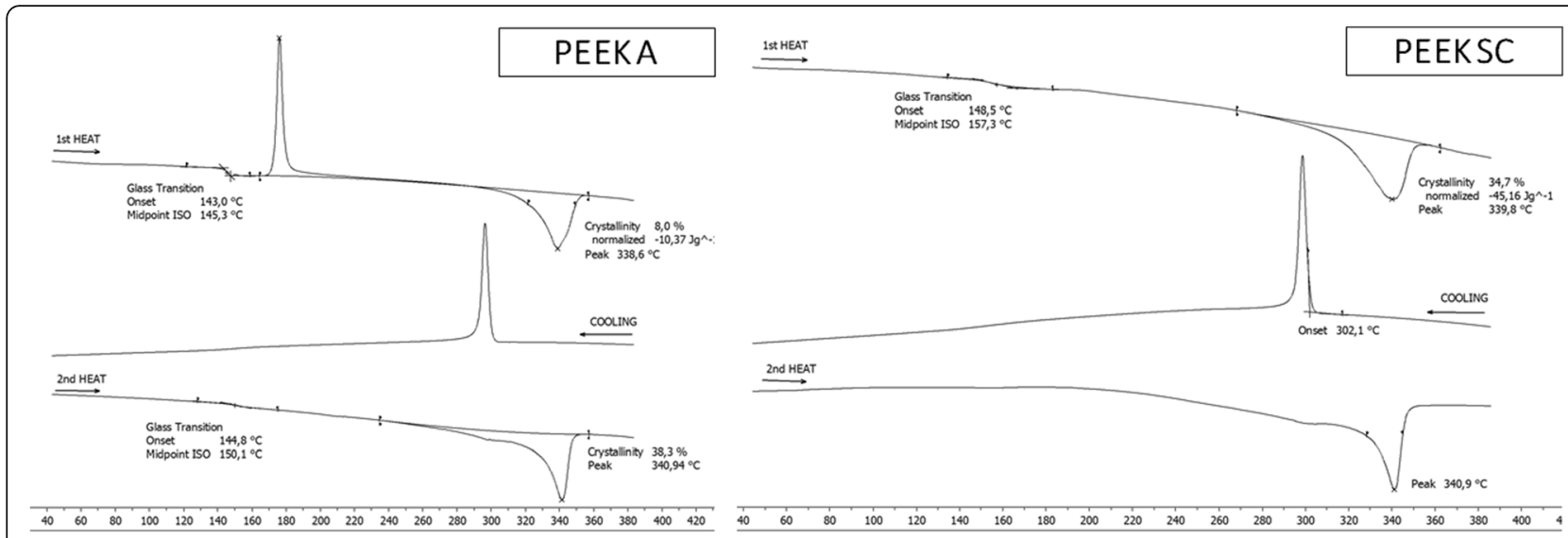

Fig. 1 DSC analysis of PEEK A and PEEK SC

Fricke et al. [8] reported that plasma treatment can significantly affect the surface roughness of polymer substrates. To quantify the expected surface roughness modification, 3D profilometry measurements were performed on both nontreated and plasma-treated interlayer films. Due to the initial roughness of the selected layer, profilometry was preferred over AFM. The profilometer used was a KAR TENCOR P17, and a scanning area of $50 \mu \mathrm{m}$ per $50 \mu \mathrm{m}$ was selected. Plasma treatment is also used industrially to activate polymer surfaces and consequently increase their wettability. Wettability measurements were performed by an OCA 15 contact angle system from Dataphysics. A series of 5 sessile water droplets of $2 \mu \mathrm{L}$ were deposited on the surface of each sample by means of a syringe pump. The contact angle value was extracted from the droplet shape by using a numerical fit based on the Laplace-Young model. Plasma treatment is also responsible for major surface chemical changes. X-ray photoelectron spectroscopy (XPS) was performed to track chemical surface modifications with a VG SCIENTA SES-2002 spectrometer equipped with a concentric hemispherical analyzer. The incident radiation used was generated by a monochromatic $\mathrm{Al} \mathrm{K} \alpha \mathrm{X}$ ray source $(1486.6 \mathrm{eV})$ operating at $420 \mathrm{~W}(14 \mathrm{kV}, 30$ $\mathrm{mA})$. Photoemitted electrons were collected at a take-off angle of 90 from the surface substrate, with electron detection in constant analyzer energy mode (FAT). A wide scan spectrum (survey) signal was recorded with a pass energy of $500 \mathrm{eV}$, and for high-resolution spectra $(\mathrm{C} 1 \mathrm{~s}$ and $\mathrm{O} 1 \mathrm{~s})$, the pass energy was set to $100 \mathrm{eV}$. The analyzed surface area was approximately $24 \mathrm{~mm} 2$, and the base pressure in the analysis chamber during the experiment was approximately $10-9$ mbar. The spectrometer energy scale was calibrated using the Ag 3d5/2, Au 4f7/2 and $\mathrm{Cu} 2 \mathrm{p} 3 / 2$ core level peaks, set at binding energies (BEs) of 368.2, 84.0, and $932.6 \mathrm{eV}$, respectively. Spectra were subjected to a Shirley background, and peak fitting was performed with mixed Gaussian-Lorentzian components with equal full-widthat-half maximum (FWHM) using CASAXPS version 2.3.18 software. The surface composition, expressed in atom\%, was determined using integrated peak areas of each component and took into account the transmission factor of the spectrometer, mean free path and Scofield sensitivity factors of each atom. All the BEs were referenced to the $\mathrm{C} 1 \mathrm{~s}$ peak at $285.0 \mathrm{eV}$ and are presented with a precision of $0.1 \mathrm{eV}$. The $\mathrm{O} / \mathrm{C}$ and $\mathrm{N} / \mathrm{C}$ ratios were obtained by using the values from the surface composition analysis.

In order to better understand the time contribution of the treated surface, three post-treatment time are selected for this study: 1 min, 1 days and 7 days after treatment. An interlayer film without treatment of each interlayer materials is also included in the present work (Table 1).

\section{Functionalized thermoset composite by liquid resin infusion (LRI)}

The liquid resin infusion (LRI) process is used to cocure the thermoplastic interlayer onto the TSC surface. The interlayer is first placed on the molding tool surface. Dry carbon fiber reinforcement, made of 6 plies of carbon fabric layup at $0^{\circ}$, supplied by Hexcel with the following type of yarns: warp, HexTow AS4C GP $3 \mathrm{~K}$; weft: HexTow AS4C GP $3 \mathrm{~K}$. The fabric's weave style is twill $2 / 2$ for a nominal weight of $200 \mathrm{~g} / \mathrm{m} 2$. One $600 \times 600$ $\mathrm{mm} 2$ composite plate is injected per interlayer treatment conditions. All three interlayer materials, with an area of $200,600 \mathrm{~mm} 2$, are integrated on each plate. Once the dry carbon fiber reinforcement was reached with a peel ply, resin distribution media and a vacuum bag completed the setup. The setup was placed in a $2 \mathrm{~m} 3$ oven from SAT Thermique, with an accuracy of $+/-5{ }^{\circ} \mathrm{C}$ at $410{ }^{\circ} \mathrm{C}$. An ISOJET injection machine composed of a pressured heated tank of $25 \mathrm{~L}$, a resin flow rate control system and a heated transfer pipe was fully controlled automatically through a Schneider Citect/SQL monitoring automate. 
Table 1 Description of performed treatments condition on the thermoplastic interlayer

\begin{tabular}{lllll}
\hline Plasma treatment (treatment time 1 min) & None & Yes & Yes & Yes \\
\hline Waiting treatment time after & N/A & 1 min & 1 day \\
PEEK A & PEEK A_NT & PEEK A_T1M & PEEK A_T1D \\
PEEK SC & PEEK SC_NT & PEEK SC_T1M & PEEK SC_T1D \\
\hline
\end{tabular}

The selected thermoset resin is RTM6-2, a bicomponent supplied by Hexcel. The curing cycle has been adapted to achieve resin polymerization above the PEEK $\mathrm{T}_{g}$ and below the recrystallization temperature of PEEK A. This cycle should promote the interlayer/TSC interface by molecular diffusion [19]. The thermal cycle of 2 $\mathrm{h}$ at $150{ }^{\circ} \mathrm{C}+2 \mathrm{~h} @ 180{ }^{\circ} \mathrm{C}$ with $5{ }^{\circ} \mathrm{C} / \mathrm{min}$ heating ramp rate was selected. The applied recipe is described in Table 2.

On Fig. 2 the functionalized TSC surface is shown after demolding. It should be noted that the nontreated PEEK SC configuration presents no adhesion after demolding, which is why no welding tests are possible. The plates are water jets cut to a size of $100 \mathrm{~mm} \times 170$ $\mathrm{mm}$ and then welded in the next stage.

\section{Infrared welding process for dissimilar join IR welding principle}

IR welding experiments were carried out using a FRIMO Infrared-Welding Machine ECO800 equipped with a welding tool enabling the assembly of two $100 \mathrm{~mm}$ long composite plates with an overlap of $12.7 \mathrm{~mm}$. The welding line was $170 \mathrm{~mm}$ wide. Single lap shear (SLS) samples were cut in a later stage through water jet cutting with a width of $25 \mathrm{~mm}$.

The welding tool is composed of upper and lower molds (cf. Figure 3), and the plates are positioned through a vacuum gripper. Both molds are fixed on a mobile table, enabling the definition of their position in the vertical direction at each process step. A mobile heating frame was able to move along the horizontal direction. On both sides of the heating frame, a set of infrared lamps was fixed. Each lamp is controlled individually, enabling control of the power as a function

Table 2 LRI main process parameters

\begin{tabular}{lll}
\hline Parameters & Value & Unit \\
\hline Outgassing temperature & 120 & ${ }^{\circ} \mathrm{C}$ \\
Outgassing vacuum level & 1 & $\mathrm{mbar}$ \\
Outgassing time & 15 & $\mathrm{~min}$ \\
Injection mold temperature & 120 & ${ }^{\circ} \mathrm{C}$ \\
Tank and tube temperature & 120 & ${ }^{\circ} \mathrm{C}$ \\
Resin flow rate & 50 & $\mathrm{~g} / \mathrm{min}$ \\
Vacuum during injection & 50 & $\mathrm{mbar}$ \\
Injected mass & 500 & $\mathrm{~g}$ \\
\hline
\end{tabular}

of time. By dissimilar material welding, the cycle times of the upper and lower sets of IR lamps are adapted to the thermal profile required by each material melting behavior.

\section{IR welding process for dissimilar material welding}

For dissimilar welding, the principle (cf. Figure 4) consists of heating each surface to assemble though an appropriate thermal cycle by individually controlling shortwave infrared emitters on the thermoset composite side and the thermoplastic composite side. Our approach consists of heating the thermoplastic composite up to the decompaction of approximately half of the initial material thickness and heating the thermoset composite side just before the end of the cycle as quickly as possible, enabling the fusion of the thermoplastic film without permanent major degradation of the thermoset composite substrate. In this work, two different heating cycle times are proposed: $27 \mathrm{~s}$ at $90 \%$ of the maximum infrared lamp power for the TPC and $17 \mathrm{~s}$ for the TSC. The TSC heating cycle starts after a $10 \mathrm{~s}$ delay compared to the TPC heating cycle start.

Figure 5 shows the thermal profile of both the welded surface and back surface of the TPC and TSC. Type K thermocouples with a $0.25 \mathrm{~mm}$ diameter were positioned on the surface to weld of each welding partner, as well as between the welding partner and the tool. A SEFRAM DAS 240 data logger was used for temperature acquisition with a sampling rate of $20 \mathrm{~ms}$.

\section{Thermal degradation of the TS matrix}

Prior to the welding of TSC with TPC, a more in-depth study of the effect of IR light on the resin alone needs to be performed, as such materials are sensitive to highenergy light and high temperatures, which cause severe degradation and damage. The modification during the IR treatment was tracked by FTIR in reflection mode to assess the chemical variation. FTIR spectroscopy was performed on the surface of the as-manufactured resin at different IR radiation times from 1 to $15 \mathrm{~s}$. From the spectrum, we can notice an increase in the peaks at $1660 \mathrm{~cm} 1$ and the appearance of a shoulder at $1735 \mathrm{~cm}$ 1 , which are related to the formation of carbonyl groups linked to thermal degradation when the sample is subjected to IR radiation in the presence of oxygen [7, 24]. Moreover, a decrease in the bond at $1050 \mathrm{~cm} 1$ with increasing irradiation time can be attributed to the epoxy 

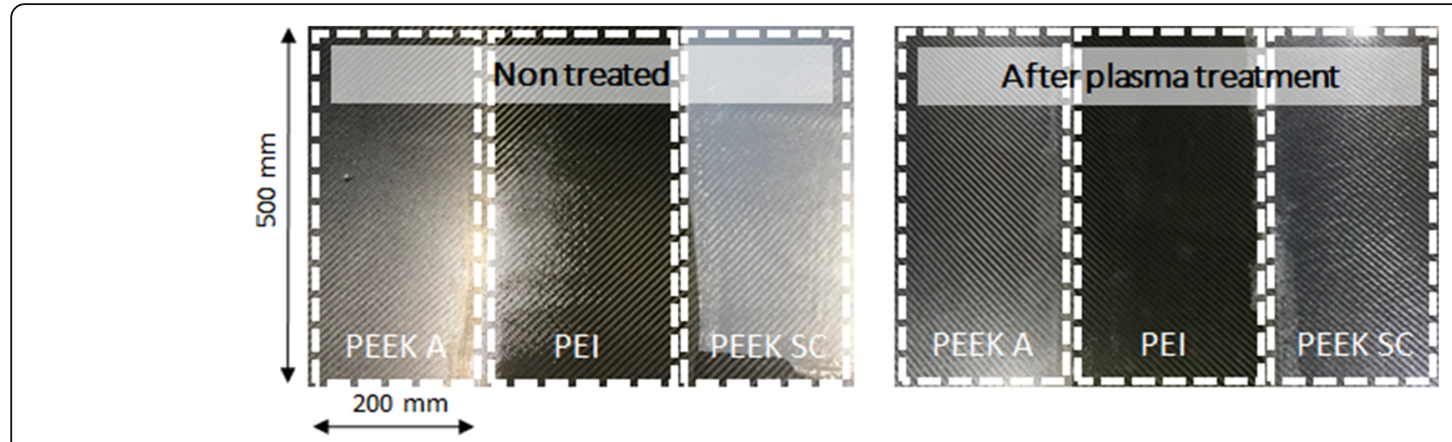

Fig. 2 Functionalized TSC views after demolding

backbone ether bridge. Such a decrease can be assigned to chain scission and indicates the degradation/decomposition of the resin under IR light. By using high-energy IR irradiation, the surface of the resin is modified by a thermal degradation mechanism in which oxidation and chain scission occur. Such an observation can explain the failure in the thermoset composite observed in the next section. For future applications, the control of the power of the IR lamp will be optimized to avoid degradation while applying enough energy to weld the material (Fig. 6).

\section{Results and discussion}

\section{Surface functionalization of TS composites}

\section{Interlayer roughness}

PEEK SC shows a significantly higher effect of plasma treatment on surface roughness than PEEK A or PEI. The root mean square $(\mathrm{Sq})$ value was similar before and after plasma treatment, with values of $0.0213 \mu \mathrm{m}$ and $0.0209 \mu \mathrm{m}$, respectively. In contrast, the kurtosis (Sku) value describing the sharpness of the roughness profile is strongly different. In the case of nontreated PEEK SC, the Sku value is 7.25, which is characteristic of a spiked height distribution. For plasma-treated PEEK SC, the Sku value is much lower, approximately 2.73. Here, the height distribution is skewed above the mean plane. Following plasma treatment, the initial primary roughness of the PEEK SC as received is complemented by a secondary roughness. PEEK A and PEI present a similar trend with a shift of the height distribution towards lower values.

The values of the measured 3D roughness are summarized in Table 3. PEEK SC shows a significantly higher effect of plasma treatment on surface roughness than PEEK A or PEI. The Sq is similar before and after plasma treatment, with values of $0.0213 \mu \mathrm{m}$ and $0.0209 \mu \mathrm{m}$, respectively. In contrast, the Sku describing the sharpness of the roughness profile is strongly different. In the case of nontreated PEEK SC, the Sku is 7.25, which is characteristic of a spiked height distribution. For plasma-treated PEEK $\mathrm{SC}$, the Sku is much lower, approximately 2.73. The analysis of the skewness value, describing the skewness of the topographic height distribution, confirms that following plasma treatment, the initial primary roughness of the PEEK SC as received is complemented by a secondary roughness. An Ssk value comparison between the asreceived and plasma-treated interlayers shows a significant decrease for the three interlayer materials. The rate at smaller heights was higher with plasma treatment than without plasma treatment. The Ssk values of PEEK A and

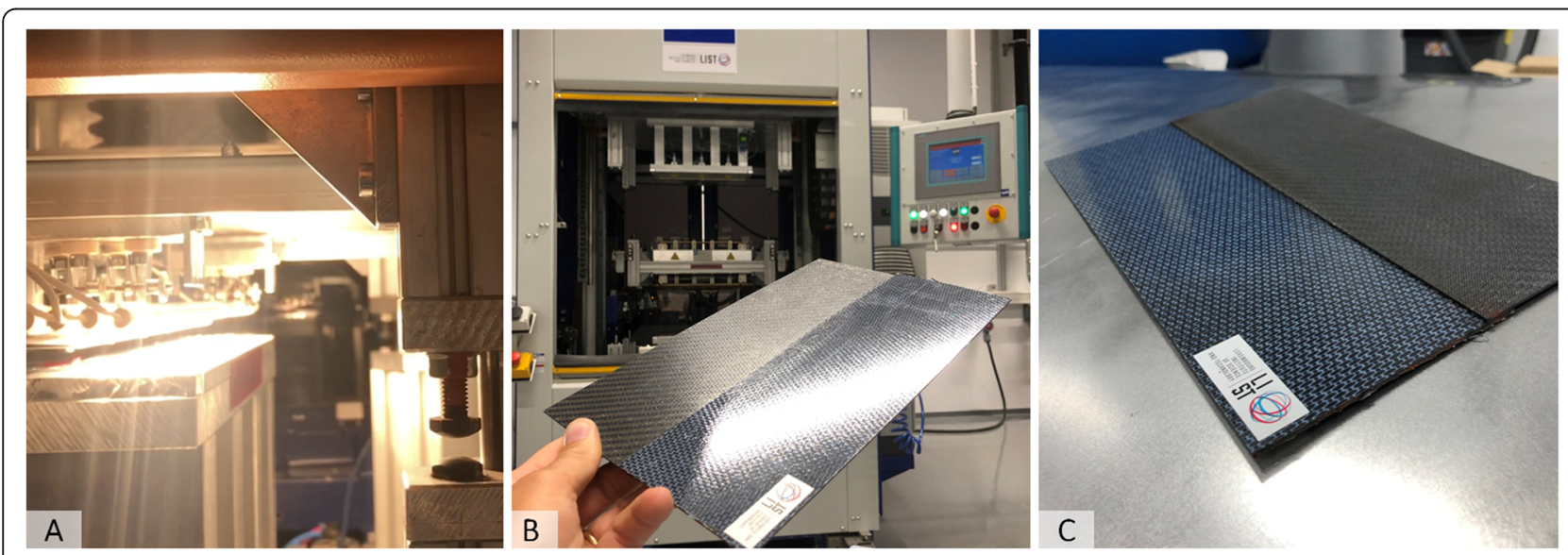

Fig. 3 a View of the lower tool during the heat phase; b IR welding equipment; c TPC/TSC welded plate 


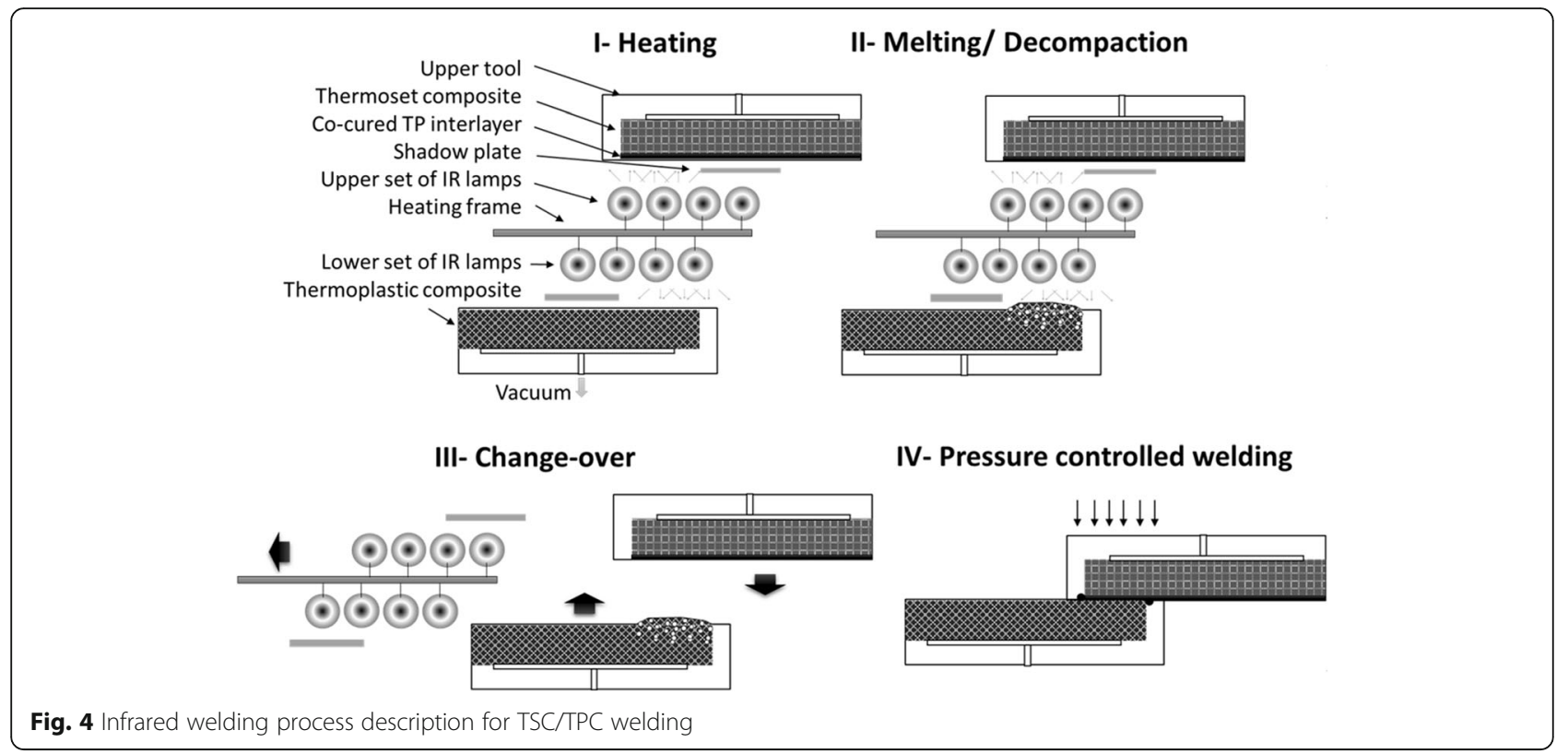

PEI present a similar trend with a shift of the height distribution towards lower values.

The analysis of the Abbot-Firestone curve [13] provides a more complete understanding of the plasma-induced 3D roughness (Fig. 7). For PEEK A and PEI, the height distribution shift is visible. The shift for PEEK SC of the height distribution is dramatic. This phenomenon can be explained by the plasma etching of the amorphous phase only, in accordance with the SEM observations of Zhang et al. [28], where a plasma-treated surface of PEEK allows the observation of better defined spherulites.

\section{Durability of the surface energy}

Surface analysis of the interlayer was performed prior at and after treatment. Water contact angle (WCA) measurements and surface free energy results are depicted in Figs. 8 and 9. Before plasma treatment, PEI, PEEK A and PEEK SC surfaces feature a WCA approximately $90.3^{\circ}, 91.3^{\circ}$ and $96.1^{\circ}$, and a SFE of $40.0,43.5$ and $47.0 \mathrm{mN} /$ $\mathrm{m}$ respectively. After plasma treatment, WCA decreased significantly to $26.9^{\circ}, 33.3^{\circ}$ and $34.3^{\circ}$, and increased to 65.9 , 63.0 and $62.0 \mathrm{mN} / \mathrm{m}$ respectively for PEI, PEEK A and PEEK SC. As the WCA and SFE increase in the same manner, plasma treatment mainly introduces polar functions at the surface such as oxygen groups [1]. The dispersive part measured is nearly constant for all surfaces. Moreover, to evaluate the possible hydrophobic recovery of such surfaces, the same analysis was performed after 1 and 7 days. The WCA and SFE go again trend in the same direction, and a decrease is observed, but the values are

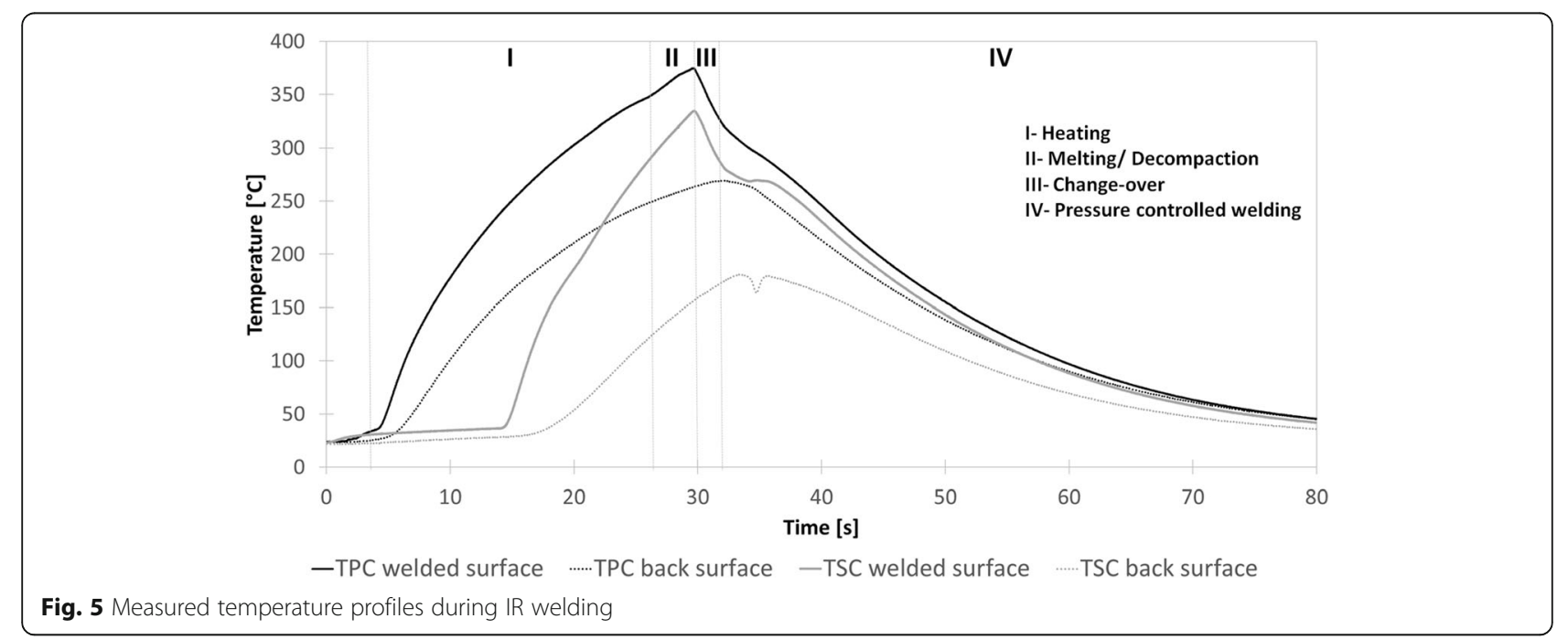




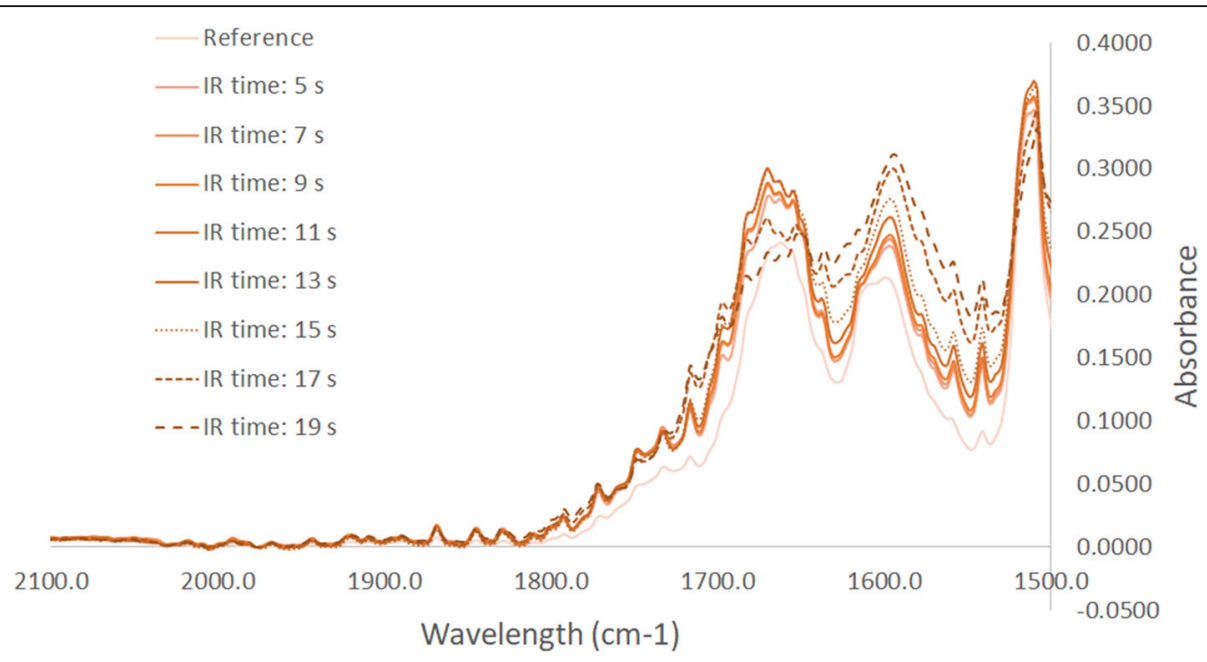

Fig. 6 FTIR normalized results for pure RTM6-2 as function of the exposure time to infrared radiation

still higher than the initial values. This clearly demonstrates the formation of stable hydrophile functional groups based mainly on oxygen at the surface of all interlayers and specifically on PEEK. In addition to the contact angle, extreme surface analysis was performed to elucidate the chemical changes occurring during plasma treatment.

\section{Durability of the chemical surface modification} investigation

To further investigate the chemical changes occurring at the surface of the interlayer XPS investigation was performed and depicted in Figs. 10 and 11 based on the $\mathrm{O} /$ $\mathrm{C}$ and $\mathrm{N} / \mathrm{C}$ ratios. The $\mathrm{O} / \mathrm{C}$ ratio increased from 0.18 to
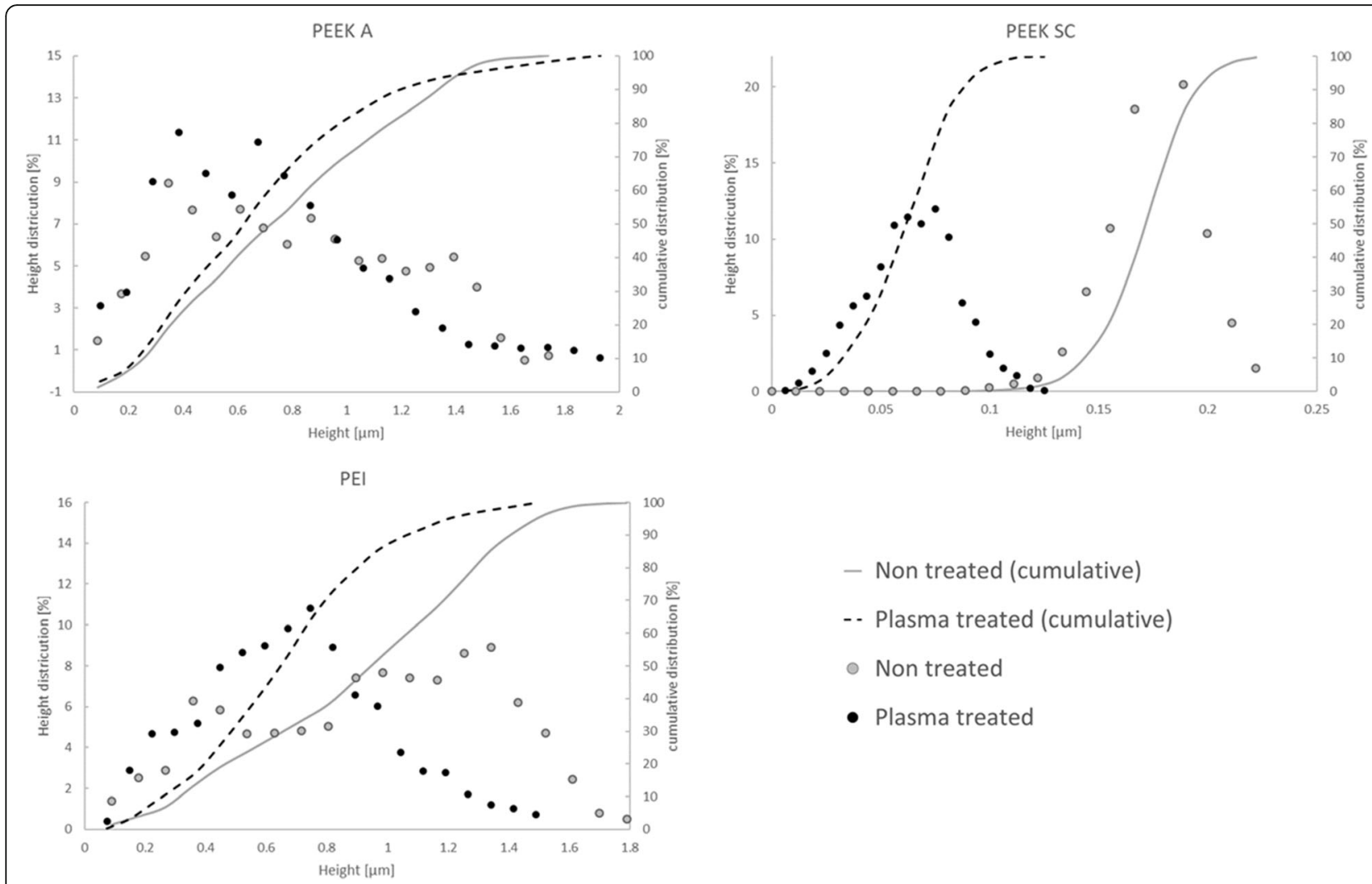

- Non treated (cumulative)

-- Plasma treated (cumulative)

- Non treated

- Plasma treated

Fig. 7 Abbot-Firestone curves for PEEK A, PEEK AC and PEl before and after plasma treatment 
Table 3 3D roughness values as received and after plasma treatment

\begin{tabular}{lllllll}
\hline & PEEK & PEEK & PEEK & PEEK & PEI_NT & PEI_T1D \\
& A_NT & A_T1D & SC_NT & SC_T1D & & \\
\hline Sq $[\mu \mathrm{m}]$ & 0.403 & 0.391 & 0.0213 & 0.0209 & 0.408 & 0.296 \\
Ssk $[-]$ & -0.244 & -0.789 & 0.966 & 0.0807 & 0.242 & -2.991 \\
Sku $[-]$ & 2.03 & 3.37 & 7.26 & 2.73 & 2.04 & 2.72 \\
Sa $\underline{[\mu \mathrm{m}]}$ & 0.343 & 0.309 & 0.0162 & 0.0168 & 0.345 & 0.237 \\
\hline
\end{tabular}

0.31 and from 0.05 to 0.08 for PEI. The same trends were observed for PEEK_A and PEEK_SC the ratio is twice that of the initial values after treatment. Such results are in good agreement with the literature highlighting the insertion of oxygen functionality at the surface of the polymer during atmospheric plasma treatment. The incorporation of nitrogen is very low in all samples. After storage of all sample for 1 and 7 days, a decrease in the $\mathrm{O} / \mathrm{C}$ ratio is observed; however, the ratio is still higher than the initial values. Such results confirm the trend observed previously in WCA and SFE, highlighting the stability of the oxygen functionalities grafted at the surface of all PEI and PEEK samples even a few days of storage. By using plasma treatment, which is a fast (1 min), dry and easy technique to implement, the surface of the three interlayers was modified. This could foster interpenetration with the thermoset, and consequently increase the adhesion with the TS composites during the co-curing process.

\section{Analysis of the surface functionalized TS composites}

A pressure-controlled FEI Quanta FEG 200 scanning electron microscope (SEM) from FEI Company was used to obtain information about the microstructure in cross sections of the samples. Samples were embedded in epoxy casting resin and subsequently ground and polished until a scratch-free surface was obtained. Figure 12 highlights a cross-section of a sample with an interlayer at the surface as observed by SEM. The visible interlayer thickness was measured from the SEM image, and the measurement was reproduced five times along the length of the interlayer. The average measured thickness and the associated standard deviation are reported in Table 4. For PEEK A, the standard deviation can be explained by the relative initial surface roughness. For PEI, the standard deviation is mainly due to the difficulty of clearly fixing the limit between the PEI and the thermoset resin. Concerning the PEI interlayer, the average thickness, calculated from 5 interlayer thickness measurements, decreased for each interlayer surface condition. Before co-curing, the asreceived PEI thickness was approximately $50 \mu \mathrm{m}$. After co-curing, the average visible PEI thickness was approximately $40 \mu \mathrm{m}$ before and after plasma treatment. As previously discussed, the miscibility/compatibility between the resin and the PEI interlayer explains the changes in the thickness measured by SEM. During the co-curing phase, the resin can, before its gelation point, interpenetrate and interdiffuse through the PEI interlayer and create semiinterpenetrating networks [22, 11, 9]. However, no real difference can be observed and related to plasma treatment. In contrast to PEI, the initial thickness of the PEEK A interlayer does not exhibit any change during co-curing since the same thickness of approximately $25 \mu \mathrm{m}$ was observed both before and after. Moreover, a clear difference in the grayscale range of the micrograph indicates a small diffusion distance, probably on the submicron-scale, of the thermoset resin into the PEEK interlayer. Although the plasma treatment does not demonstrate any improvement in the diffusion distance at the micron scale between the resin and the PEEK interlayer, the interface is smooth,

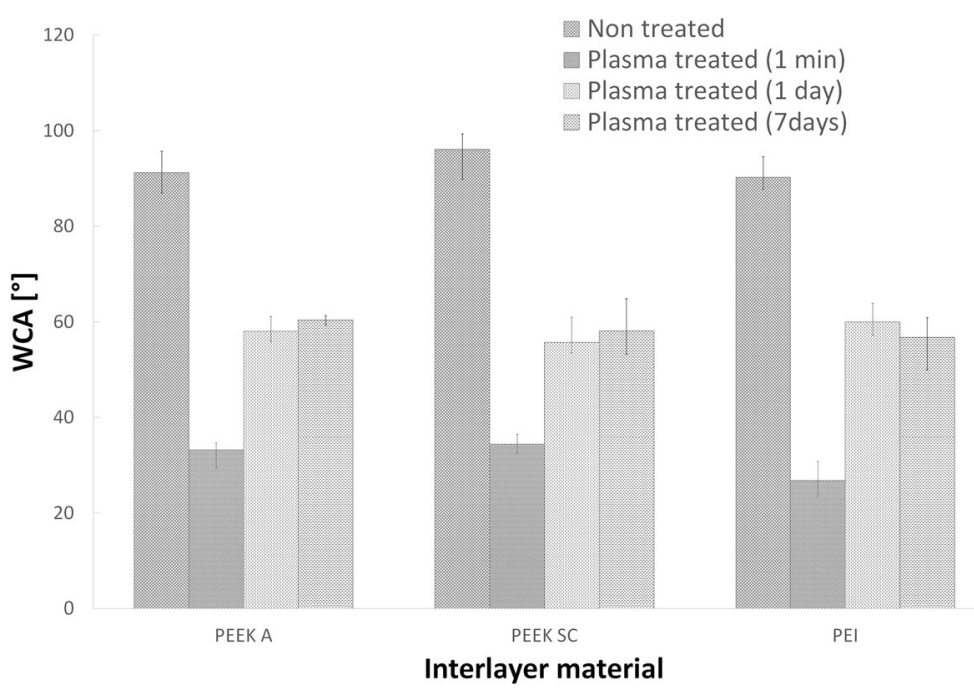

Fig. 8 Wettability depending on waiting time after plasma treatment 

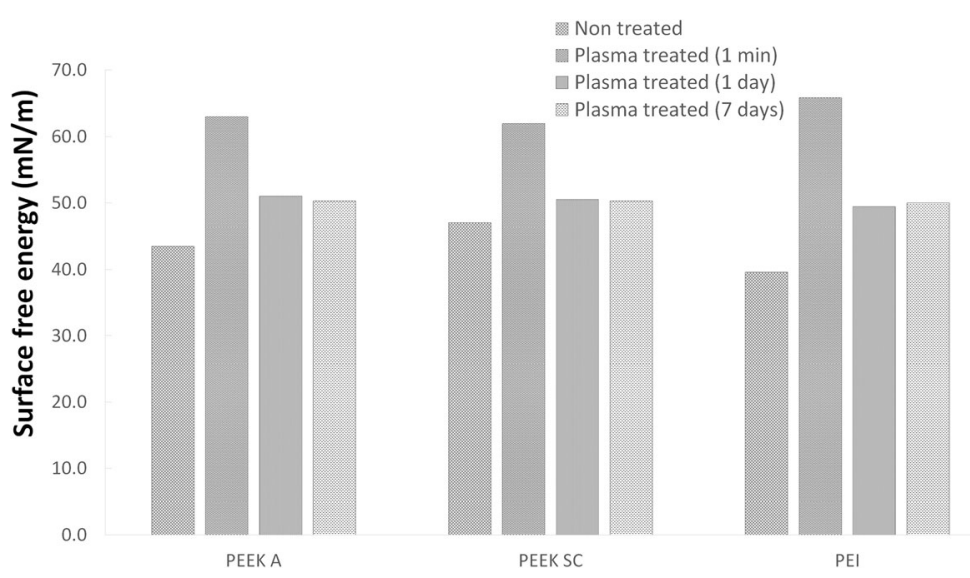

Fig. 9 Surface free energy depending on waiting time after plasma treatment

without any voids or gaps, arguing for good adhesion. Interdiffusion probably occurs at the molecular or nanoscale and is beyond of the resolution of the SEM. Concerning the PEEK SC interlayer without plasma treatment, no adhesion occurs: the PEEK SC interlayer can be easily separated by hand, and no picture is provided. This configuration does not allow interpenetration with the resin during the manufacturing process. Unexpectedly, after plasma treatment, adhesion between the interlayer and the resin during co-curing occurs, as observed by SEM. Furthermore, no decohesion is visible between the two components. The joint line seems smooth and without any defects. The initial thickness was effectively observed by SEM without any additional sample etching preparation and was even on the same order of magnitude as the initial thickness of $25 \mu \mathrm{m}$. The surprising effect of plasma on co-cured PEEK SC has to be linked with the drastic change in surface roughness, mainly the height distribution. An explanation could be that the amorphous accessible surface was increased by plasma etching, enabling the interdiffusion of the thermoset onto the amorphous phase of the PEEK SC. The initial roughness of the PEEK $\mathrm{SC}$ allowed deeper analysis of the etching mechanism by SEM or AFM.

\section{Welded dissimilar joint performances Single lap shear (SLS) test result}

The double cantilever beam (DCB) test is recognized as the most representative test for characterizing the joint interface of welded joints [3]. The implementation of the

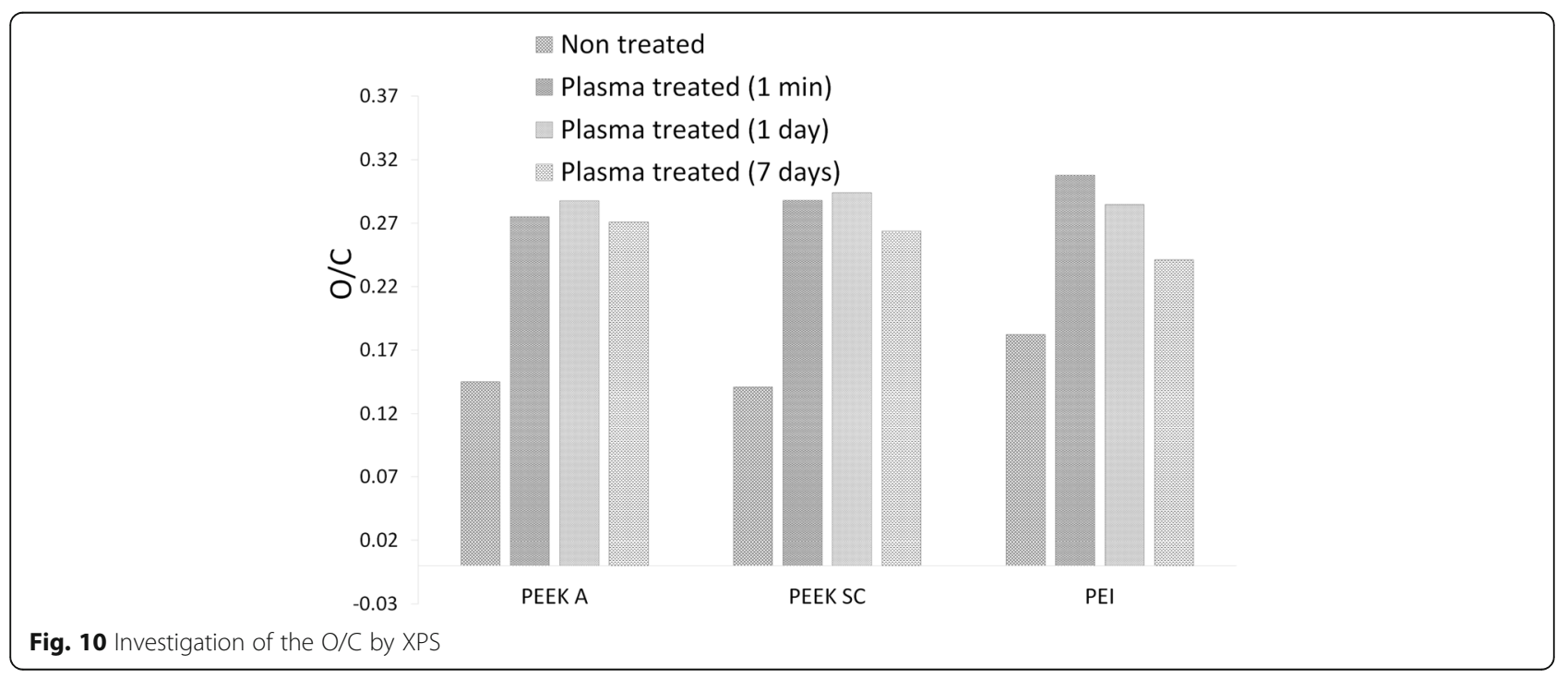




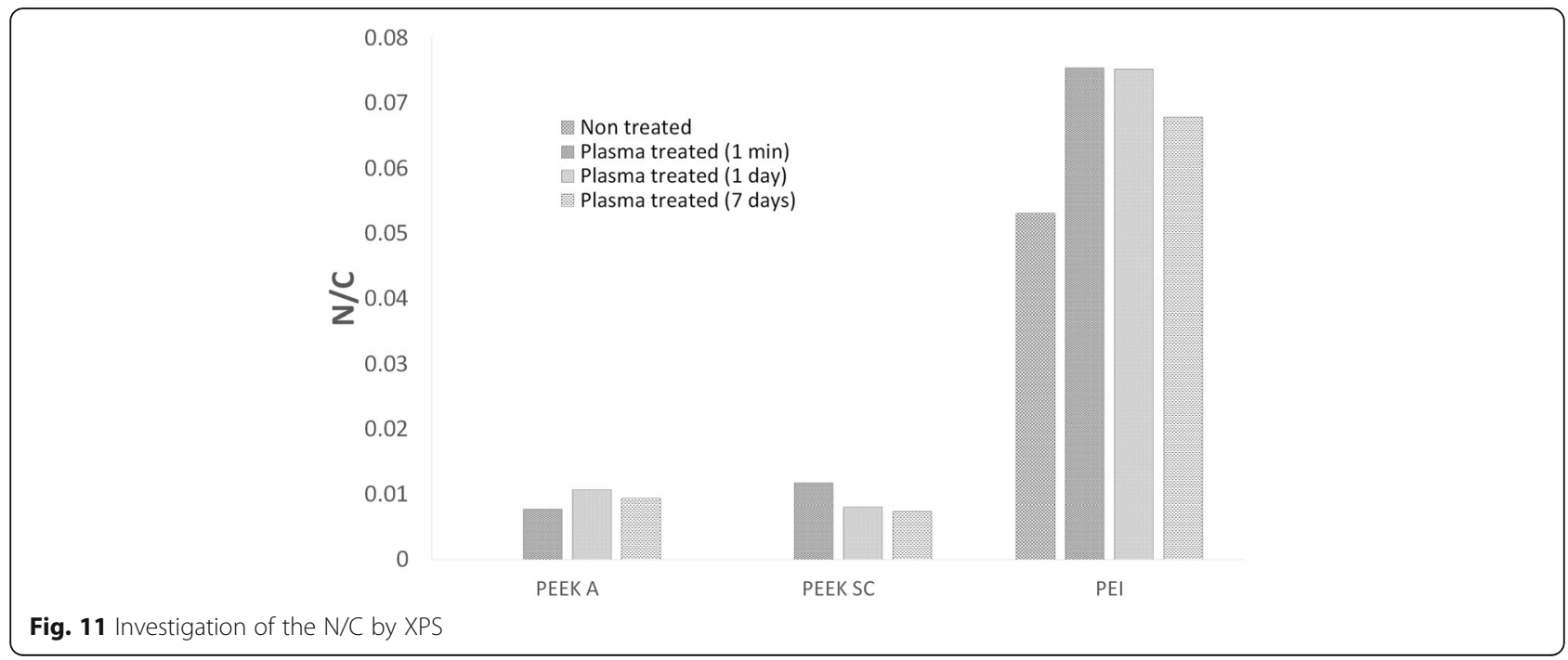

DCD test for dissimilar joints is too limiting, as additional devices are required to avoid any sample rotation during the test.

SLS mechanical testing was selected to characterize the mechanical performance of the welded joint. This test is common and is effectively used to address hybrid joint performance. The SLS test was originally developed to investigate the bonding strength of homogeneous joints. In hybrid joints, the stiffness of both weld partners are different, and the constraint along the welding line is not symmetrical. Here, only the calculated shear strength can be compared, as the weld partner combinations are identical.

Figure 13 represents the obtained results from SLS mechanical tests performed on each sample. The value for untreated PEI is approximately $17.5 \mathrm{MPa}$, and the

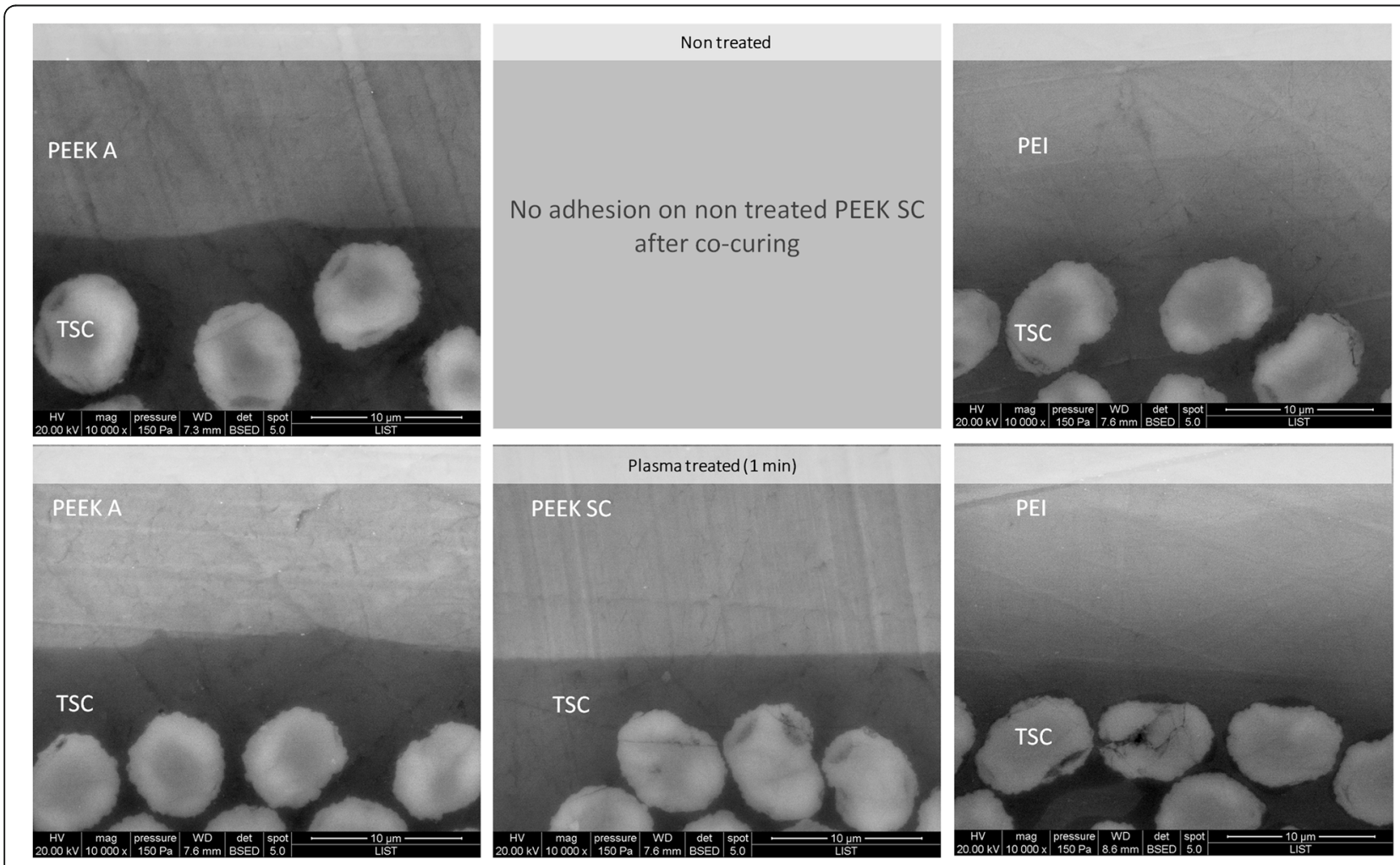

Fig. 12 Cross section view by SEM of the functionalized TSC 
Table 4 Average visible interlayer thickness after co-curing

\begin{tabular}{llll}
\hline & PEEK A & PEEK SC & PEI \\
\hline Initial theoretical value & $25 \mu \mathrm{m}$ & $25 \mu \mathrm{m}$ & $50 \mu \mathrm{m}$ \\
Non treated & $25.5 \mu \mathrm{m}+/ 0.7$ & $\mathrm{x}$ & $39.8 \mu \mathrm{m}+/ 1.4$ \\
Plasma treated (1 min) & $25.2 \mu \mathrm{m}+/ 0.7$ & $24.3 \mu \mathrm{m}+/ 0.2$ & $39.7 \mu \mathrm{m}+/ 0.7$ \\
Plasma treated (1 day) & $25.4 \mu \mathrm{m}+/ 0.9$ & $24.4 \mu \mathrm{m}+/ 0.4$ & $42.1 \mu \mathrm{m}+/ 2.0$ \\
Plasma treated (7 days) & $24.9 \mu \mathrm{m}+/ 0.4$ & $25.0 \mu \mathrm{m}+/ 0.3$ & $41.7 \mu \mathrm{m}+/ 2.9$ \\
\hline
\end{tabular}

values for all treated samples are closer to $19 \mathrm{MPa}$. A slight increase occurs in the plasma-treated sample, which cannot be directly explained by the surface treatment itself, as failure occurs through the TSC instead at the interlayer interface. The same trends were observed for amorphous and semicrystalline PEEK, and a slightly higher value was reached after plasma treatment. Regarding the standard deviation of the lap shear test, this slight trend is considered a component of the welding process uncertainties and does not represent a direct effect of the plasma treatment waiting time after plasma treatment. Surprisingly, the waiting time after plasma treatment has no major impact on the resulting mechanical properties. Except for untreated PEEK SC, where no adhesion occurs with the resin during co-curing, the resulting values of the mechanical performance of both types of PEEK are not far from those of PEI, which means that the IR welding process combined with appropriate surface activation is a powerful technique to strongly bond thermosets to thermoplastic composites.

\section{Failure mode analysis}

To investigate the failure mode after the mechanical test, visual observations were performed on the test samples.
Three types of failure modes were observed: adhesive failure at the TPC/interlayer interface, adhesive failure at the interlayer/TSC interface and cohesive failure through the TSC.

Figure 14 shows the failure surface of both welded partners using PEEK A material as the interlayer, with and without plasma treatment. It is interesting to note that without plasma treatment, the PEEK A interlayer presents local adhesive failure with the TSC. This failure mode is visible in two of the five tested SLS samples in this configuration. In this configuration, all three failure modes are observed. It is clear that plasma treatment plays a valuable role not only for PEEK SC material but also for PEEK A. With plasma treatment, no adhesive failure at the interlayer/TSC interface was observed. The failure mode was dominated by failure through the TSC composite.

Figure 15 shows the failure mode for both PEEK SC and PEI in the case of plasma treatment of the interlayer. Only cohesive failure through the TSC is observed. The same observation was made in analysis of the nontreated PEI. The first ply of the TSC is still welded after the SLS test.

Time after treatment appears to present no major influence. Similarly, wettability cannot be considered a major driving parameter, as no relationship between surface energy and mechanical performance is observed.

Plasma treatment affects PEEK A and PEI. Local adhesive failure between PEEK A and TSC without plasma treatment is no longer present after plasma treatment. No effect of the time after plasma treatment is observable. PEEK SC shows the dramatic effect of plasma treatment. With no adhesion without plasma treatment, the joints failed to fully cohere through the TSC like they do

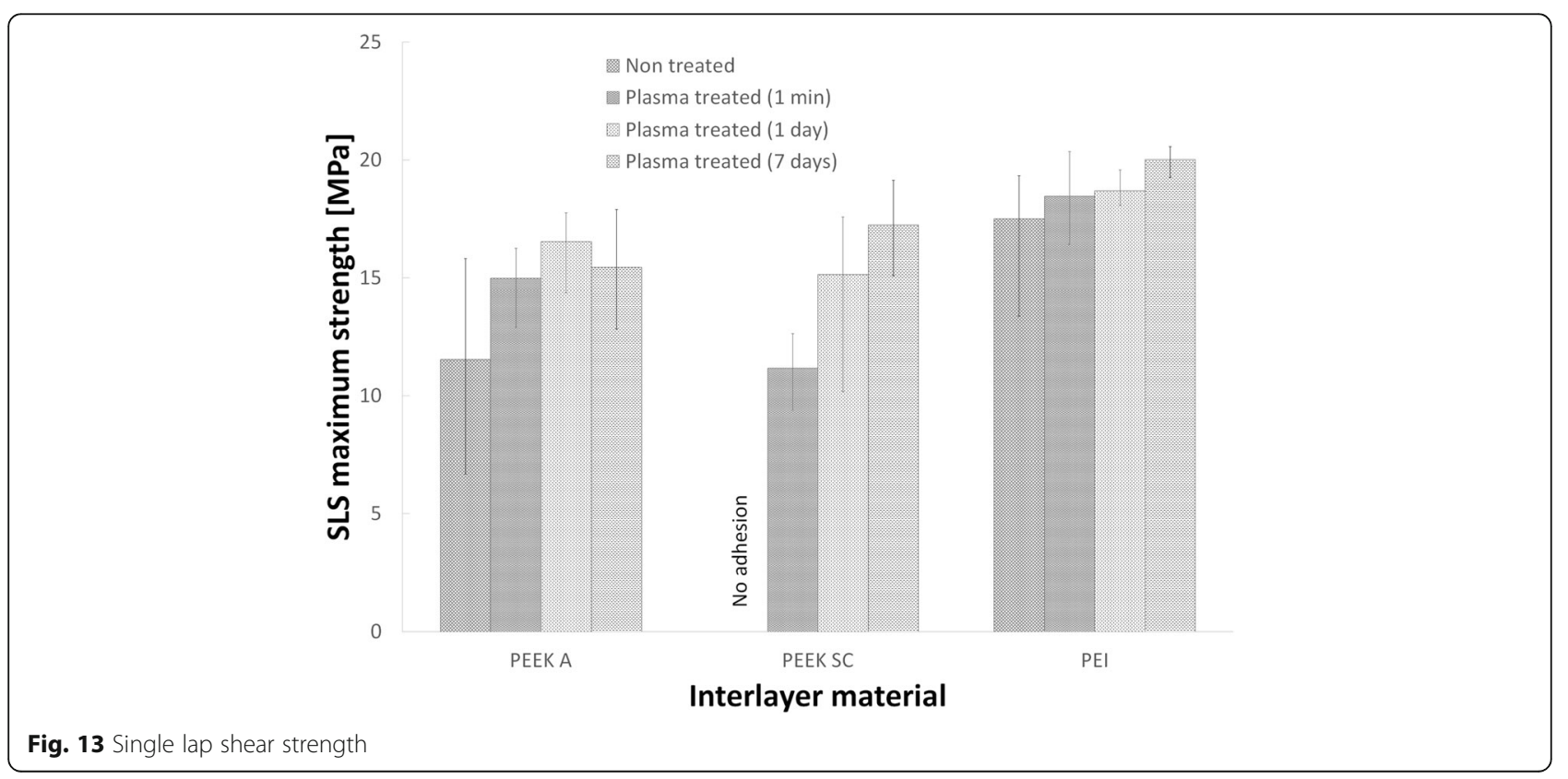



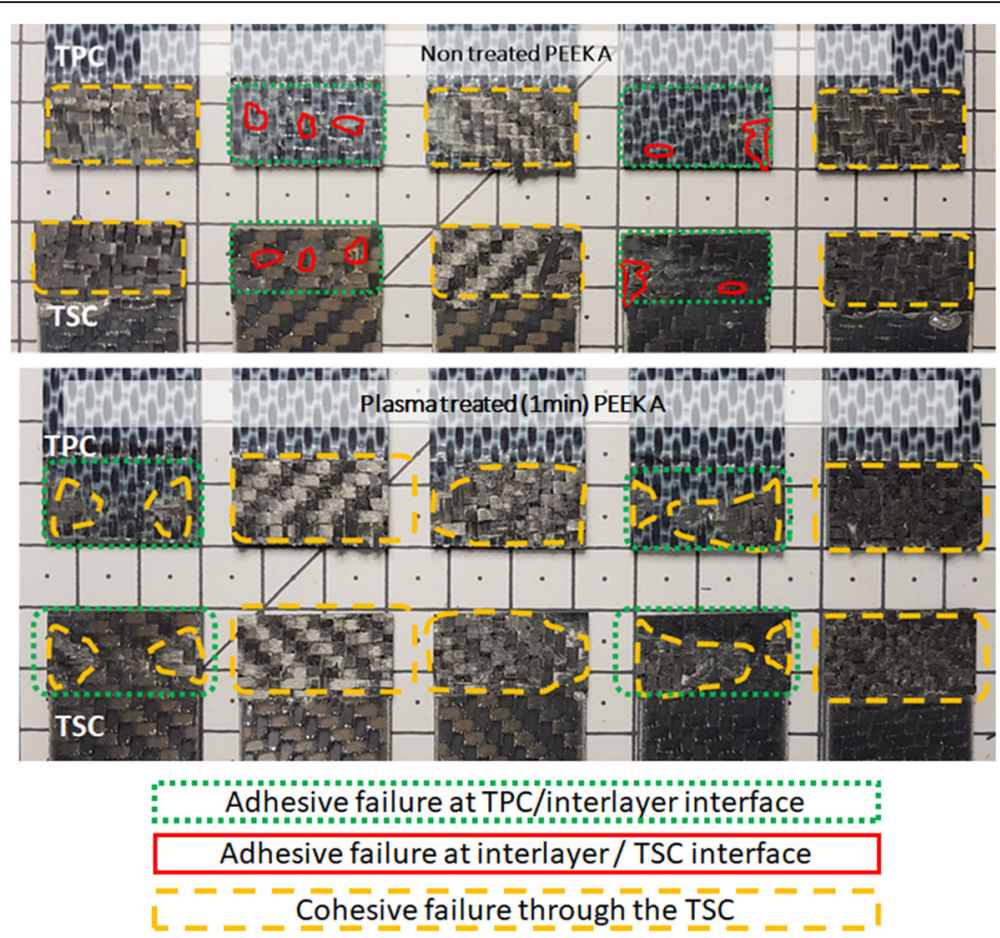

Fig. 14 Failure mode analysis on nontreated and plasma treated PEEK A interlayer welded joints

after plasma treatment, independent of the waiting time after treatment. The interpretation of the results is limited, as cohesive failure through the TSC limits the possibility of conclusions at the interlayer interface level, particularly for the PEI interlayer. The PEEK A interlayer failure analysis highlights how plasma improves the homogeneity of the interlayer adhesion. Plasma etching could explain the gain in both homogeneity and performance. This explanation is also consistent with the observed phenomenon in the PEEK SC interlayer, where

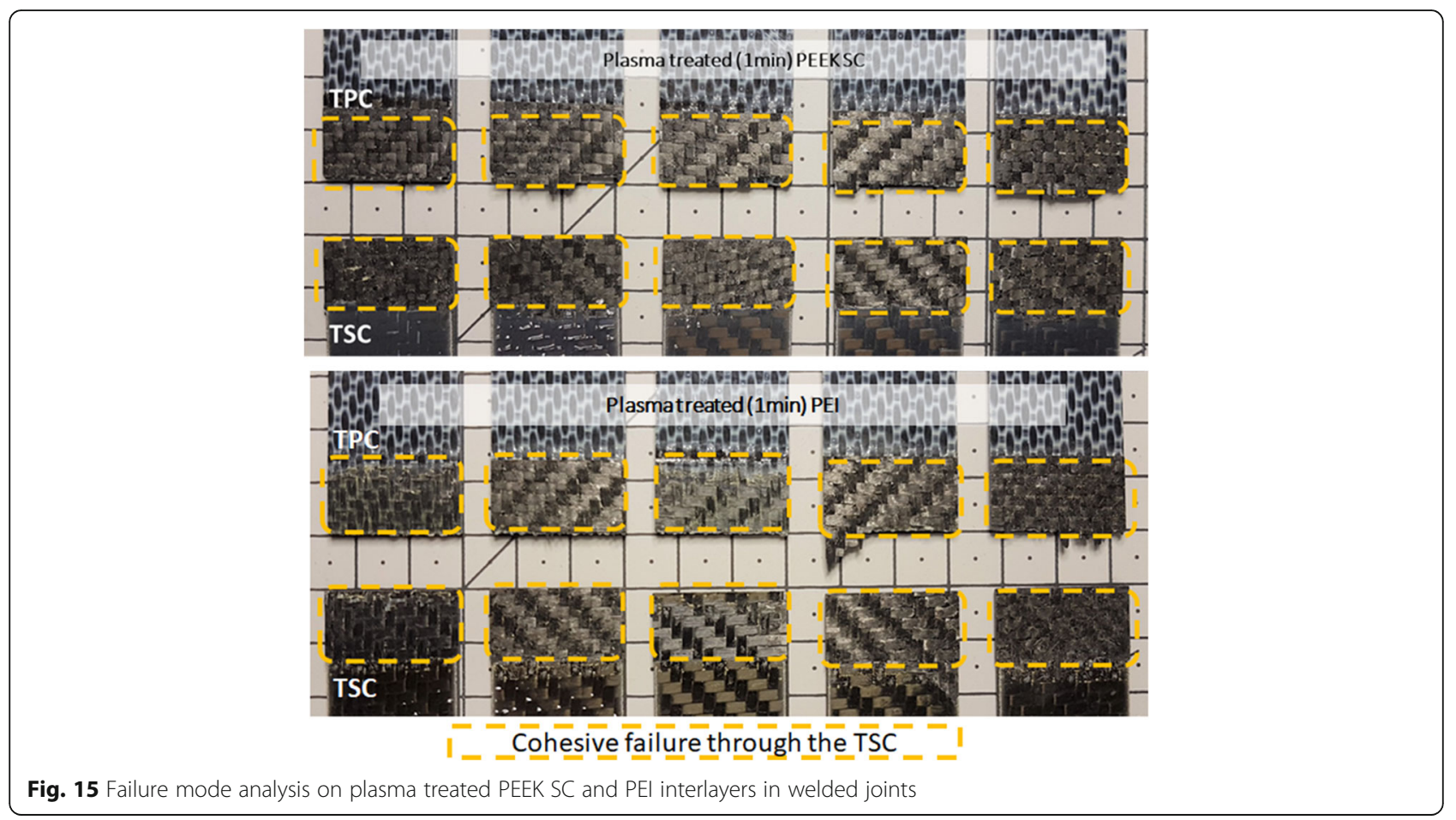


plasma etching is assumed to be the main adhesiondriving parameter.

\section{Conclusions}

An investigation of plasma chemical surface modification of three interlayer materials is presented. The durability of the chemical surface modification was analyzed. No major link has been shown between chemical modification, durability of this modification and mechanical performance.

Plasma etching of the three interlayers of interest was investigated. The analysis of the 3D topological parameters enables us to better describe plasma surface modification. PEEK SC shows a radical topological change, particularly regarding the height distribution, and a radical increase in adhesion with plasma treatment. The two phenomena are certainly strongly connected. Plasma treatment, through the etching effect, allows the interdiffusion of the thermoset. This assumption must be confirmed in a more dedicated study.

Failure analysis of the nontreated PEEK A interlayer shows miscellaneous failure locations, including through the TSC, at the co-cured interlayer interface and at the welding interface.

Diffusion of the TS matrix in the PEI interlayer was expected and was observed through the reduction of the PEI thickness after co-curing. For both PEEK A and PEEK SC, no thickness variation was observed at the microscale, even if similar levels of SLS strength were measured. Diffusion certainly occurs at the molecular or nanoscale.

Although the obtained mechanical performance is below that of industrial requirements, IR welding has been proven to be suitable for designing hybrid composites without any additional elements, unlike resistive elements and energy directors for resistance and US welding, respectively. Further research on the adhesion between the interlayer and the resin needs to be done to better understand the underlying mechanisms. In addition, the optimization of IR welding process parameters or material combinations must be performed to avoid any TSC degradation.

\section{Acknowledgments}

The authors gratefully thank Yves Fleming for 3D-Profilometry measurements and Jerome Guillot, for XPS analysis.

\section{Authors' contributions}

Henri Perrin conceived and designed the LRI in-process functionalization and IR welding experiments, analyzed and interpreted the data, wrote the paper, reviewed and edited the manuscript. Gregory Mertz: conceived, designed, performed and characterized the surface treatment experiment and contributed to writing the manuscript. Noha-Lys Senoussaoui: performed the thermal analysis experiments and contributed to writing the manuscript. Loïc Borghini performed the LRI in-process functionalization experiments and failure mode analysis. Sébastien Klein performed the IR welding experiments. Régis Vaudemont conceived, designed and performed the thermal analysis experiments and critically reviewed the manuscript. The author(s) read and approved the final manuscript.

\section{Funding}

The project leading to this application has received funding from the Clean Sky 2 Joint Undertaking under the European Union's Horizon 2020 research and innovation programme under grant agreement No 831979. All authors gratefully thank the European Commission and the Clean sky II JU.

\section{Availability of data and materials}

The datasets used and/or analyzed during the current study are available from the corresponding author on reasonable request.

\section{Declarations}

\section{Competing interests}

The authors have no competing interest.

Received: 12 October 2020 Accepted: 11 March 2021

Published online: 06 April 2021

\section{References}

1. E. Arikan, J. Holtmannspötter, T. Hofmann, H.J. Gudladt, Vacuum UV of polyetheretherketone (PEEK) as a surface pre-treatment for structural adhesive bonding. J. Adhes. 96(10), 917-944 (2020). https://doi.org/10.1080/ 00218464.2018 .1545646

2. A.C.A. Asséko, B. Cosson, É. Lafranche, F. Schmidt, Y.L. Maoult, Effect of the developed temperature field on the molecular interdiffusion at the interface in infrared welding of polycarbonate composites. Compos. Part B 97, 53-61 (2016). https://doi.org/10.1016/j.compositesb.2016.04.064

3. J. Avenet, A. Levy, J.L. Bailleul, S.L. Corre, J. Delmas, Adhesion of high performance thermoplastic composites: development of a bench and procedure for kinetics identification. Compos. A: Appl. Sci. Manuf. 138(April), 106054 (2020). https://doi.org/10.1016/j.compositesa.2020.106054

4. I.D. Baere, K. Allaer, S. Jacques, W.V. Paepegem, J. Degrieck, Interlaminar behavior of infrared welded joints of carbon fabric-reinforced polyphenylene sulfide. Polym. Composites 33(7), 1105-1113 (2012). https:// doi.org/10.1002/pc.22238

5. W. Ballout, P.V. Velthem, D. Magnin, E. Henry, M. Sclavons, T. Pardoen, C. Bailly, Specific influence of polyethersulfone functionalization on the delamination toughness of modified carbon fiber reinforced polymer processed by resin transfer molding. Polym. Eng. Sci. 59(5), 996-1009 (2019). https://doi.org/10.1002/pen.25055

6. A.P. da Costa, E.C. Botelho, M.L. Costa, N.E. Narita, J.R. Tarpani, A review of welding technologies for thermoplastic composites in aerospace applications. J. Aerosp. Technol. Manage. 4(3), 255-265 (2012). https://doi. org/10.5028/jatm.2012.04033912

7. A. Doblies, B. Boll, B. Fiedler, Prediction of thermal exposure and mechanical behavior of epoxy resin using artificial neural networks and Fourier transform infrared spectroscopy. Polymers 11(2), 363 (2019). https://doi. org/10.3390/POLYM11020363

8. K. Fricke, S. Reuter, D. Schroder, V.S. von der Gathen, K.D. Weltmann, T. von Woedtke, Investigation of surface etching of poly(ether ether ketone) by atmospheric-pressure plasmas. IEEE Trans. Plasma Sci. 40(11), 2900-2911 (2012). https://doi.org/10.1109/TPS.2012.2212463

9. X. Gao, Z. Huang, H. Zhou, D. Li, Y. Li, Y. Wang, Higher mechanical performances of CF/PEEK composite laminates via reducing interlayer porosity based on the affinity of functional s-PEEK. Polym. Compos. 40(9), 3749-3757 (2019). https://doi.org/10.1002/pc.25236

10. G. Gardiner, Welding thermoplastic composites : CompositesWorld. Composite World, 1-12 (2018)

11. M.T. Heitzmann, M. Hou, M. Veidt, L.J. Vandi, R. Paton, Morphology of an interface between Polyetherimide and epoxy prepreg. Adv. Mater. Res. 393395(September), 184-188 (2012). https://doi.org/10.4028/www.scientific. net/AMR.393-395.184

12. R.O. Johnson, H.S. Burlhis, Polyetherimide: a new high-performance thermoplastic resin. J. Polym. Sci. Polym. Symp. 70(1), 129-143 (1983). https://doi.org/10.1002/polc.5070700111

13. J. Kundrak, K. Gyani, V. Bana, Roughness of ground and hard-turned surfaces on the basis of 3D parameters. Int. J. Adv. Manuf. Technol. 38(1-2), 110-119 (2008). https://doi.org/10.1007/s00170-007-10869

14. A. Kuzminova, A. Shelemin, O. Kylián, A. Choukourov, H. Valentová, I. Krakovský, J. Nedbal, D. Slavínská, H. Biederman, Study of the effect of atmospheric pressure air dielectric barrier discharge on nylon 6,6 foils. 
Polym. Degrad. Stab. 110, 378-388 (2014). https://doi.org/10.1016/j. polymdegradstab.2014.10.001

15. J.F. Lamèthe, P. Beauchêne, L. Léger, Polymer dynamics applied to PEEK matrix composite welding. Aerosp. Sci. Technol. 9(3), 233-240 (2005). https://doi.org/10.1016/j.ast.2005.01.008

16. W. Leahy, V. Barron, M. Buggy, T. Young, A. Mas, F. Schue, T. McCabe, M. Bridge, Plasma surface treatment of aerospace materials for enhanced adhesive bonding. J. Adhes. 77(3), 215-249 (2001). https://doi.org/10.1080/ 00218460108030739

17. A. Pascual, M. Toma, P. Tsotra, M.C. Grob, On the stability of PEEK for short processing cycles at high temperatures and oxygen-containing atmosphere. Polym. Degrad. Stab. 165, 161-169 (2019). https://doi.org/10.1016/j. polymdegradstab.2019.04.025

18. R. Phillips, T. Glauser, J.A.E. Månson, Thermal stability of PEEK/carbon fiber in air and its influence on consolidation. Polym. Composites 18(4), 500-508 (1997). https://doi.org/10.1002/pc.10302

19. H. Shi, J. Sinke, R. Benedictus, Surface modification of PEEK by UV irradiation for direct co-curing with carbon fibre reinforced epoxy prepregs. Int. J. Adhes. Adhes. 73, 51-57 (2017). https://doi.org/10.1016/j.jjadhadh.2016.07.017

20. K. Terpi, A.E. Wi, M. Jurak, Influence of nitrogen plasma treatment on the wettability of polyetheretherketone and deposited chitosan layers. Adv. Polym. Technol. 37(6), 1557-1569 (2018). https://doi.org/10.1002/adv.21813

21. E. Tsiangou, S.T. de Freitas, I.F. Villegas, R. Benedictus, Ultrasonic welding of epoxyto polyetheretherketonebased composites: Investigation on the material of the energy director and the thickness of the coupling layer. J. Compos. Mater. 54(22), 3081-3098 (2020). https://doi.org/10.1177/0021 998320910207

22. L.J. Vandi, M. Hou, M. Veidt, R. Truss, M. Heitzmann, R. Paton, Interface diffusion and morphology of aerospace grade epoxy co-cured with thermoplastic polymers. 28th Congress of the International Council of the Aeronautical Sciences 2012, ICAS 2012 3(January 2012), 1984-1992 (2012)

23. P.V. Velthem, W. Ballout, D. Daoust, M. Sclavons, F. Cordenier, E. Henry, D. Dumont, V. Destoop, T. Pardoen, C. Bailly, Influence of thermoplastic diffusion on morphology gradient and on delamination toughness of RTMmanufactured composites. Compos. A: Appl. Sci. Manuf. 72, 175-183 (2015). https://doi.org/10.1016/j.compositesa.2015.02.012

24. I.F. Villegas, P.V. Rubio, On avoiding thermal degradation during welding of high-performance thermoplastic composites to thermoset composites. Compos. A: Appl. Sci. Manuf. 77, 172-180 (2015). https://doi.org/10.1016/j. compositesa.2015.07.002

25. R. Vodicka, Thermoplastics for airframe applications: a review of the properties and repair methods for thermoplastic composites. (1996)

26. C. Voto, M. Lannone, Environmental resistance of amorphous bonded thermoplastic joints -the utilization of advanced composites in military aircraft (1992)

27. X. Xiong, P. Zhao, R. Ren, Z. Zhang, X. Cui, S. Ji, Resistance welded composite joints strengthened by carbon fiber felt: Mechanical properties, failure modes and mechanism. Mater. Res. Express 6(8), 085323 (2019). https://doi.org/10.1088/2053-1591/ab226b

28. S. Zhang, F. Awaja, N. James, D.R. McKenzie, A.J. Ruys, A comparison of the strength of autohesion of plasma treated amorphous and semi-crystalline PEEK films. Polym. Adv. Technol. 22(12), 2496-2502 (2011). https://doi.org/1 0.1002/pat.1791

\section{Publisher's Note}

Springer Nature remains neutral with regard to jurisdictional claims in published maps and institutional affiliations.

\section{Submit your manuscript to a SpringerOpen ${ }^{\circ}$ journal and benefit from:}

- Convenient online submission

- Rigorous peer review

- Open access: articles freely available online

- High visibility within the field

- Retaining the copyright to your article

Submit your next manuscript at $\boldsymbol{\nabla}$ springeropen.com 